\title{
Genotype-4 hepatitis $E$ in a human after ingesting roe deer meat in South Korea
}

\author{
Ja Yoon Choi', Jeong-Mi Lee', Yun Won Jo', Hyun Ju Min', Hyun Jin Kim', Woon Tae Jung', Ok Jae Lee', Haesun Yun², \\ and Yeong-Sil Yoon ${ }^{2}$ \\ ${ }^{1}$ Department of Internal Medicine, Gyeongsang National University School of Medicine, Jinju; ${ }^{2}$ Division of Enteric and Hepatitis Viruses, \\ Korea Centers for Disease Control and Prevention, Korea National Institute of Health, Osong, Korea
}

The recent increase in the number of cases of indigenous hepatitis $E$ virus (HEV) infection highlights the importance of identifying the transmission routes for the prevention of such infections. Presented herein is the first case of acute HEV infection after ingesting wild roe deer meat in South Korea. A 43-year-old male presented with abdominal discomfort and jaundice. He had not recently traveled abroad, but had eaten raw roe-deer meat 6-8 weeks before the presentation. On the 7th day of hospitalization the patient was diagnosed with acute viral hepatitis E. Phylogenetic analysis of his serum revealed genotype-4 HEV. This case supports the possibility of zoonotic transmission of HEV because the patient appears to have been infected with genotype-4 HEV after ingesting raw deer meat. (Clin Mol Hepatol 2013;19:309314)

Keywords: Genotype 4 hepatitis E; Roe deer; South Korea

\section{INTRODUCTION}

Hepatitis E virus (HEV) has four genotypes. Of these four types, genotype 1 has caused epidemic outbreaks in Asia and Africa and genotype 2 is usually discovered in western Africa. Both genotype 1 and 2 are found exclusively in humans. ${ }^{1}$ On the other hand, genotypes 3 and 4 are usually isolated from sporadic hepatitis $E$ in developed countries, and also found in swine, deer, wild boar populations. ${ }^{2,3}$ Sporadic infection in non-endemic areas such as developed countries has been known to be due to an influx from foreign countries. However, some reports of locally acquired acute viral hepatitis $E$ in people with no history of travel to endemic regions have recently increased in non-endemic areas. ${ }^{4,5}$ Autochthonous sporadic HEV infections in a non-endemic area mostly give no clue as to their sources despite the diagnosis of acute viral hepatitis $\mathrm{E}$, rendering the transmission routes undecided.

Of the viruses that cause acute viral hepatitis, HEV is known to be the only virus to have animal reservoirs. Since the discovery of HEV in swine, HEV has also been isolated from chickens, deers, mongooses, rabbits and rats, supporting zoonotic transmission and prompting its investigation. ${ }^{6,7}$ We report here a case of acute viral hepatitis $E$ that occurred after ingestion of raw meat of a wild roe deer in the absence of contact with another hepatitis patient or travel to an endemic area.

\section{Abbreviations:}

HEV, hepatitis E virus; LT, liver transplantation

\section{Corresponding author: Hyun Ju Min}

Department of Internal Medicine, Gyeongsang National University School of Medicine, 79 Gangnam-ro, Jinju 660-702, Korea

Tel. +82-55-750-8885, Fax. +82-55-758-9122

E-mail; lyreju@naver.com 


\section{CASE REPORT}

A 43-year-old male presented with abdominal discomfort for 3 weeks and jaundice lasting 1 week. He had a past history of diabetes mellitus, which had been diagnosed 3 years prior to admission to our hospital. However, he arbitrarily stopped taking hypoglycemic agents. The patient was a heavy alcohol drinker, with the consumption of 2 to 3 bottles of Soju, distilled liquor, 4 to 5 times a week. He denied any travel outside South Korea in the preceding years. About 6-8 weeks before hospitalization, he ingested raw meat (about $300 \mathrm{~g}$ ) of a captured wild roe deer inhabiting in Gyeongnam province with his friends, who enjoyed hunting on a regular basis.

Physical examination on admission was generally normal, except for jaundice. Mild tenderness was only noted in the epigastric area. Initial laboratory data showed white blood cell count of $4.88 \times 10^{3} / \mathrm{mm}^{3}$ (polymorphonuclear neutrophils, 57.2\%; lymphocytes, 36.4\%; and eosinophils, 1.5\%), elevated serum total bilirubin level of $12.3 \mathrm{mg} / \mathrm{dL}$, serum aspartate aminotransferase (AST) level of 1,637 IU/L, serum alanine aminotransferase (ALT) level of 1,949 IU/L, random glucose level of $220 \mathrm{mg} / \mathrm{dL}$ and HbA1c level of $10.8 \%$. Hepatitis B surface (HBs) antigen, immunoglobulin M (IgM) anti-hepatitis B core antigen, anti-hepatitis C virus (HCV), HCV RNA (RT PCR) were all negative with positive anti-HBs. As a result of IgM anti-hepatitis A virus (HAV) was negative with positive immunoglobulin $\mathrm{G}(\mathrm{IgG})$ anti-HAV, acute hepatitis A could be excluded. Abdominal computed tomography showed findings compatible with secondary changes in acute hepatitis, and fatty infiltration with splenomegaly, which implied concurrent alcoholic liver disease. Seven days after admission, results of IgM anti-HEV and IgG anti-HEV were both positive, the optical density value of IgM anti-

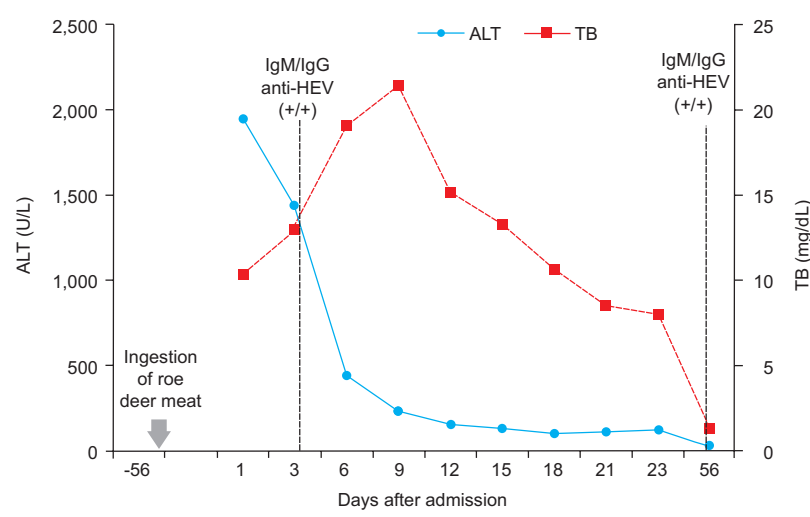

Figure 1. Patient's clinical course with changes in ALT, TB and results of IgM / IgG anti-HEV. ALT, alanine aminotransferase; TB, total bilirubin; HEV, hepatitis E virus.
HEV of 3.656 (cut-off value: 0.276 ) and IgG anti-HEV of 3.384 (cut-off value: 0.375 ), which confirmed the diagnosis of acute viral hepatitis E. IgM anti- HEV and IgG anti- HEV were measured by a commercial immunoassay (HEV IgM and HEV IgG ELISA, Genelabs Diagnostic Pte. Ltd, Singapore). The serum total bilirubin peaked at $24.3 \mathrm{mg} / \mathrm{dL}$ and rapidly decreased. The levels of AST and ALT were highest at the time of admission and then showed a rapid decrease. Twenty-three days after admission, the patient was discharged with a total bilirubin of $8.06 \mathrm{mg} / \mathrm{dL}$, AST of $130 \mathrm{IU} / \mathrm{L}$ and ALT of 133 IU/L (Fig. 1). Two months after discharge, IgM antiHEV and IgG anti-HEV were both still positive with the optical density value of IgM anti-HEV of 3.315 (cut-off value: 0.282 ) and IgG anti-HEV of 2.753 (cut-off value: 0.375 ). Diagnosis of hepatitis E was confirmed by the detection of both IgM and IgG anti-HEV in serial samples and by the detection of serum HEV RNA.

\section{Detection of HEV genome in patient's serum}

Viral RNA was extracted from $140 \mu \mathrm{L}$ of anti-HEV IgM-positive serum in phosphate-buffered saline using a QIAamp viral RNA

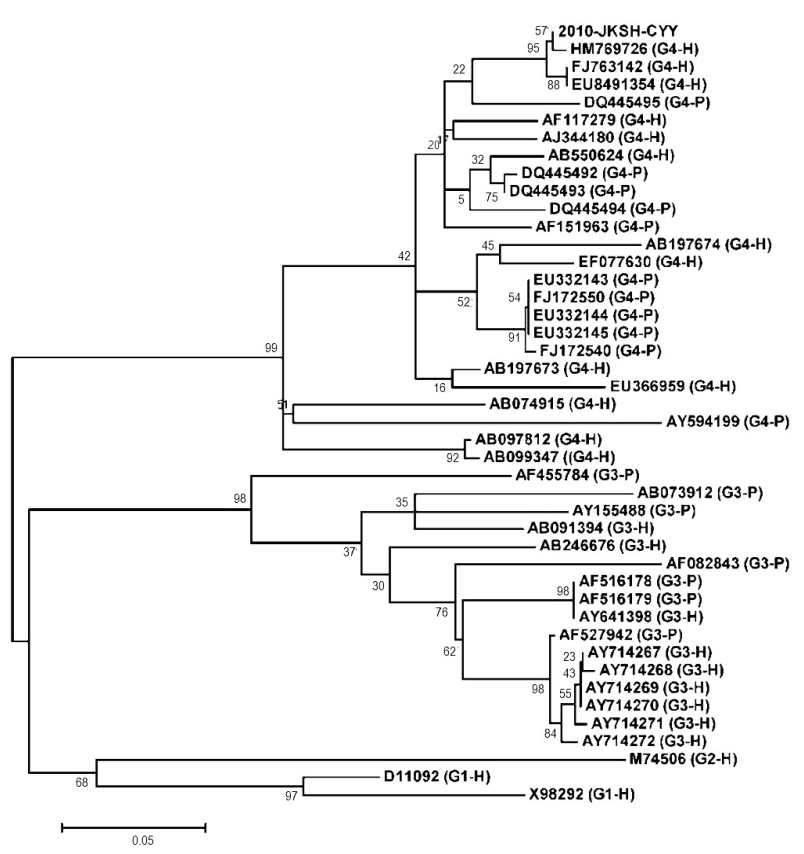

Figure 2. A phylogenetic tree constructed by the neighbor-joining method based on the ORF2 sequence of the Korean HEV in question, 2010-JKSH-CYY (HM769726), and 42 HEV reference strains with genotypes 1 - 4 (G1-G4). All strains were separated into four groups according to their genotype. $\mathrm{H}$ : isolated from humans; P: isolated from pigs. Sequence analysis was conducted using the software VectorNTI and MEGA 5.04. Bootstrap values are indicated for the major nodes as a percentage of the data obtained from 1000 resamplings. 
Ja Yoon Choi, et al. Genotype-4 hepatitis E in a human after ingesting roe-deer meat in South Korea

Table 1. Comparison of the HEV isolates obtained in the present study (2010-JKSH-CYY) with 42 human and swine HEV reference strains, based on ORF2 sequence

\begin{tabular}{|c|c|c|c|c|c|}
\hline No. & Accession No. (Human) & Accession No. (Pig) & Genotype & Country & Homology (\%) \\
\hline 1 & D11092 & & $1 b$ & China (Uighur) & 74 \\
\hline 2 & X98292 & & $1 c$ & India & 74 \\
\hline 3 & M74506 & & $2 a$ & Mexico & 78 \\
\hline 4 & & AF082843 & $3 a$ & USA (Midwest) & 73 \\
\hline 5 & & AB073912 & $3 b$ & Japan (Tochigi) & 76 \\
\hline 6 & AB091394 & & $3 b$ & Japan (Kanagawa) & 77 \\
\hline 7 & & AF455784 & $3 g$ & Kyrgyzstan & 76 \\
\hline 8 & & AY115488 & $3 j$ & Canada (Ontario) & 76 \\
\hline 9 & AB246676 & & 3 & Japan (Tokyo) & 77 \\
\hline 10 & & AF516178 & $3 a$ & Korea & 76 \\
\hline 11 & & AF516179 & $3 a$ & Korea & 76 \\
\hline 12 & & AF527942 & $3 a$ & Korea & 77 \\
\hline 13 & AY641398 & & $3 a$ & Korea & 76 \\
\hline 14 & AY714267 & & $3 a$ & Korea & 76 \\
\hline 15 & AY714268 & & $3 a$ & Korea & 76 \\
\hline 16 & AY714269 & & $3 a$ & Korea & 76 \\
\hline 17 & AY714270 & & $3 a$ & Korea & 76 \\
\hline 18 & AY714271 & & $3 a$ & Korea & 77 \\
\hline 19 & AY714272 & & $3 a$ & Korea & 75 \\
\hline 20 & AB074915 & & $4 c$ & Japan (Saitama) & 83 \\
\hline 21 & AB097812 & & $4 c$ & Japan (Hokkaido) & 87 \\
\hline 22 & AB099347 & & $4 c$ & Japan (Tochigi) & 87 \\
\hline 23 & & AY594199 & $4 d$ & China (Uighur) & 82 \\
\hline 24 & AB197673 & & 4 & Japan & 91 \\
\hline 25 & AB197674 & & 4 & Japan & 89 \\
\hline 26 & EF077630 & & 4 & China (Changchun) & 90 \\
\hline 27 & EU366959 & & 4 & China (Beijing) & 91 \\
\hline 28 & FJ763142 & & 4 & Korea (Gyeonggi-do) & 98 \\
\hline 29 & EU849134 & & 4 & Korea (Gyeonggi-do) & 97 \\
\hline 30 & AF151963 & & 4 & China & 93 \\
\hline 31 & DQ445492 & & 4 & China (Changchun) & 94 \\
\hline 32 & DQ445493 & & 4 & China (Changchun) & 94 \\
\hline 33 & DQ445494 & & 4 & China (Changchun) & 93 \\
\hline 34 & DQ445495 & & 4 & China (Changchun) & 94 \\
\hline 35 & & EU332143 & 4 & China (Heilongjiang) & 94 \\
\hline 36 & & EU332144 & 4 & China (Heilongjiang) & 94 \\
\hline 37 & & EU332145 & 4 & China (Heilongjiang) & 94 \\
\hline 38 & & FJ172540 & 4 & China (Heilongjiang) & 92 \\
\hline 39 & & FJ172550 & 4 & China (Inner Mongolia) & 93 \\
\hline 40 & AF117279 & & 4 & Taiwan & 93 \\
\hline 41 & AJ344180 & & 4 & China & 92 \\
\hline 42 & AB550624 & & 4 & China (Inner Mongolia) & 93 \\
\hline
\end{tabular}


mini-kit (Qiagen, Hilden, Germany) according to the manufacturer's instructions. Purified RNA was used to generate the ORF2 of HEV using One-Step RT-PCR with a PLATINUM Taq Kit (Takara, Shiga, Japan). Briefly, RT-PCR was performed on $5 \mu \mathrm{L}$ of purified RNA from serum in $50 \mu \mathrm{L}$ of $2 \times$ reaction mix with $0.2 \mu \mathrm{M}$ each primer (forward: 5' aggttggcgctctgtcgaga-3'; reverse: 5'-acagtcggctcgccattgg $\left(-3^{\prime}\right)$. Reverse transcription was performed for $30 \mathrm{~min}$ at $50^{\circ} \mathrm{C}$ and for 2 min at $94^{\circ} \mathrm{C}$ followed by 40 cycles of $94^{\circ} \mathrm{C}$ for $30 \mathrm{~s}, 55^{\circ} \mathrm{C}$ for 30 s and $72^{\circ} \mathrm{C}$ for 2 min, and a final extension step of $10 \mathrm{~min}$ at $72^{\circ} \mathrm{C}$. The second round of PCR was performed under the same conditions as the first-round PCR with $0.2 \mu \mathrm{M}$ each of the same primers. ${ }^{8}$

\section{Phylogenetic analysis}

The relationship between the sequences is shown in the den- drogram. The length of each pair of branches represents the distance between the sequences. Phylogenetic trees were constructed by the neighbor-joining method based on the ORF2 sequence. All strains were separated into four groups according to their genotypes. Sequence analysis was conducted using the software VectorNTI and MEGA 4.1 beta. Bootstrap values are indicated for the major nodes as a percentage of the data obtained from 1000 resamplings.

We identified genotype 4 human HEV from the 43-year-old Korean male patient with acute hepatitis, who had never been abroad. He was negative for serum markers of hepatitis $A, B$ and $C$ viruses and positive for anti-hepatitis $E$ virus as IgM class leading to the diagnosis of hepatitis $\mathrm{E}$, whose ORF2 nucleotide sequence from the patient was isolated. The identified Korean HEV strain named 2010-JKSH-CKK (HM769726) belonged to genotype 4, based on comparison with previously reported HEV strains

Table 2. Reported human cases of hepatitis E in Korea

\begin{tabular}{|c|c|c|c|c|c|c|c|c|}
\hline Case ref & $\begin{array}{l}\text { Age (yr) } \\
\text { /Sex }\end{array}$ & $\begin{array}{l}\text { Presenting } \\
\text { symptom }\end{array}$ & $\begin{array}{c}\text { Suspicious } \\
\text { transmission route }\end{array}$ & $\begin{array}{l}\text { IgM anti-HEV } \\
\text { (titer/cut-off) }\end{array}$ & $\begin{array}{l}\text { IgG anti-HEV } \\
\text { (titer/cut-off) }\end{array}$ & $\begin{array}{l}\text { Serum } \\
\text { HEV RNA }\end{array}$ & $\begin{array}{c}\text { Stool } \\
\text { HEV RNA }\end{array}$ & Outcome \\
\hline$\# 117$ & $27 / M$ & Fever, myalgia & UK & $+(1.22 / 0.45)$ & + & ND & ND & Recovery \\
\hline \#217 & $28 / F$ & Fever, diarrhea & Travel/India & $+(1.77 / 0.44)$ & $+(4.0 / 0.58)$ & ND & ND & Recovery \\
\hline \#317 & $34 / F$ & Jaundice & UK & $+(1.30 / 0.46)$ & $+(1.27 / 0.62)$ & ND & ND & Recovery \\
\hline \#417 & $42 / M$ & Abdominal pain & UK & $+(1.10 / 0.43)$ & $+(3.35 / 0.53)$ & ND & ND & Recovery \\
\hline \#518 & $30 / M$ & Fatigue & UK & + & - & ND & ND & Recovery \\
\hline \#618 & $25 / F$ & Jaundice, fatigue & UK & + & - & ND & ND & Recovery \\
\hline \#718 & $24 / M$ & Jaundice & Travel/India & + & - & ND & ND & Recovery \\
\hline \#818 & 29/M & Jaundice & UK & + & - & ND & ND & Recovery \\
\hline \#918 & $52 / F$ & Jaundice & UK & + & - & ND & ND & Recovery \\
\hline$\# 1018$ & $45 / M$ & Fatigue & UK & + & - & ND & ND & Recovery \\
\hline \#1118 & $48 / F$ & Jaundice & UK & + & - & ND & ND & Recovery \\
\hline$\# 1218$ & $42 / F$ & Jaundice & UK & + & - & ND & ND & Recovery \\
\hline$\# 13^{*} 18$ & $23 / F$ & Jaundice & UK & + & - & ND & ND & $\mathrm{LT}$ \\
\hline$\# 1419$ & $42 / F$ & Fever & UK & + & ND & ND & ND & Recovery \\
\hline$\# 1519$ & $33 / M$ & Fatigue & UK & + & ND & ND & ND & Recovery \\
\hline$\# 1619$ & $40 / F$ & Fatigue & UK & + & ND & ND & ND & Recovery \\
\hline$\# 178$ & $51 / F$ & Jaundice & UK & + & + & $\begin{array}{c}\text { Detected } \\
\text { genotype } 4\end{array}$ & ND & Recovery \\
\hline$\# 1822$ & $54 / \mathrm{M}$ & Jaundice & Wild boar bile juice & $+(3.62 / 0.30)$ & $+(3.73 / 0.38)$ & $\begin{array}{c}\text { Detected } \\
\text { genotype } 4\end{array}$ & Detected & Recovery \\
\hline$\# 19^{\dagger}$ & $43 / M$ & Jaundice & Roe deer meat & $+(3.66 / 0.28)$ & $+(3.38 / 0.38)$ & $\begin{array}{c}\text { Detected } \\
\text { genotype } 4\end{array}$ & ND & Recovery \\
\hline
\end{tabular}

Ref, reference; HEV, hepatitis E virus; UK, unknown; ND, not detected; LT, liver transplantation. *underlying autoimmune hepatitis. †present case. 
(Table 1, Fig. 2). When comparing the ORF2 region, HM769726 was closely related to the two strains EU849134 and FJ763142 with a nucleotide similarity of 97 and $98 \%$, respectively (Table 1). The two human strains by HEV genome from Korean patients, who had never been aboard, were isolated in Gyeonggi-do, Korea. Among swine HEV isolates, HM769726 was closely related to EU332143-45 from Heilongjiang, China (Table 1). ${ }^{9}$

\section{DISCUSSION}

In 1997, an animal strain of HEV was isolated from pig, characterized as swine HEV, which was revealed to be genetically associated with human HEV in the United States. ${ }^{6}$ Subsequently, a number of swine HEVs were isolated and proven to be closely associated genetically with human HEV. ${ }^{10,11}$ Unlike genotype 1 and 2 HEV, genotype 3 and 4 HEV are isolated from both human and animals. Recently, sporadic cases of genotype 3 and 4 hepatitis $E$ has been reported in non endemic area, such as France, ${ }^{12}$ Germany, ${ }^{13,14}$ and Japan. ${ }^{6,11,15,16}$ In Germany, an autochthonous genotype 3 HEV infection was reported even in a 5-month-old female child. ${ }^{14}$ In Japan where raw fish and uncooked or undercooked meat are part of the traditional diet, there have been some case reports of zoonotic food-borne transmission, though domestic pig, wild boar and wild deer are the main routes for autochthonous HEV infection. ${ }^{10,11}$ For example, in 2003, hepatitis E was diagnosed in a family who had previously ingested raw meat of a wild roe deer. HEV genotype 3 was isolated from the remnant raw meat and the nucleotide sequence homology of HEV was verified between the family and the meat. ${ }^{7}$ Following this event, there were some published articles about zoonotic transmission of HEV in Japan. $^{16}$

In South Korea, There have been case reports of HEV with some reports of HEV serologically diagnosed since 2002; however, only three of them including our case could detect serum HEV RNA (Table 2). ${ }^{17-20}$ In the interpretation of HEV serological test, we should consider the possibility of false-positive result especially in nonendemic areas. The detection of IgM anti-HEV in serial samples as well as serum or stool HEV RNA detection is helpful to confirm diagnosis. ${ }^{21}$ Two Korean cases of genotype 4 hepatitis $E$ reported in 2010 and 2011 are similar to our case with a nucleotide similarity of 97 and $98 \%$, respectively. ${ }^{8,22}$ Our case is the first human case of autochthonous genotype 4 hepatitis $E$ from a roe deer, while most of the HEV infections previously reported were by zoonotic transmission from a domestic pig or a wild boar in South
Korea. Accumulating data supports the notion that zoonotic transmission is the main route of autochthonous infection of HEV, which is an increasingly interesting issue.

Even with an increasing interest in acute hepatitis $\mathrm{E}, \mathrm{HEV}$ is still regarded as an infrequent cause of acute viral hepatitis. Perhaps this is because most asymptomatic patients with merely elevated levels of aminotransferase receive supportive care without a definitive diagnosis, which can possibly underestimate the incidence of hepatitis $E$. Therefore, physicians should be on the alert for HEV infection in patients with acute hepatitis of unknown etiology in developed countries. Furthermore, it is important to check whether they intake the raw meat of wild animals in patients without a travel history of HEV endemic area.

\section{Conflicts of Interest}

The authors have no conflicts to disclose.

\section{REFERENCES}

1. van Cuyck-Gandre H, Zhang HY, Tsarev SA, Clements NJ, Cohen SJ, Caudill JD, et al. Characterization of hepatitis E virus (HEV) from algeria and chad by partial genome sequence. J Med Virol 1997;53:340-347.

2. Arankalle VA, Chobe LP, Joshi MV, Chadha MS, Kundu B, Walimbe AM. Human and swine hepatitis $E$ viruses from western india belong to different genotypes. J Hepatol 2002;36:417-425.

3. Shukla P, Chauhan UK, Naik S, Anderson D, Aggarwal R. Hepatitis $E$ virus infection among animals in northern india: An unlikely source of human disease. J Viral Hepat 2007;14:310-317.

4. Kwo PY, Schlauder GG, Carpenter HA, Murphy PJ, Rosenblatt JE, Dawson GJ, et al. Acute hepatitis $\mathrm{E}$ by a new isolate acquired in the united states. Mayo Clin Proc 1997;72:1133-1136.

5. Kabrane-Lazizi Y, Zhang M, Purcell RH, Miller KD, Davey RT, Emerson SU. Acute hepatitis caused by a novel strain of hepatitis E virus most closely related to united states strains. J Gen Virol 2001;82:1687-1693.

6. Meng XJ, Purcell RH, Halbur PG, Lehman JR, Webb DM, Tsareva TS, et al. A novel virus in swine is closely related to the human hepatitis E virus. Proc Natl Acad Sci U S A 1997;94:9860-9865.

7. Tei S, Kitajima N, Takahashi K, Mishiro S. Zoonotic transmission of hepatitis E virus from deer to human beings. Lancet 2003;362:371373.

8. Yun H, Kim JS, Lee HJ, Jeong SH, Kim JS, Park SJ, et al. The complete genome sequence and molecular analysis of human hepatitis E virus genotype IV identified from a korean patient. Arch Virol 
2010;155:1003-1008.

9. Zhu G, Qu Y, Jin N, Sun Z, Liu T, Lee H, et al. Seroepidemiology and molecular characterization of hepatitis $E$ virus in jilin, china. Infection 2008;36:140-146.

10. Matsuda H, Okada K, Takahashi K, Mishiro S. Severe hepatitis E virus infection after ingestion of uncooked liver from a wild boar. J Infect Dis 2003;188:944.

11. Tamada Y, Yano K, Yatsuhashi H, Inoue O, Mawatari F, Ishibashi $H$. Consumption of wild boar linked to cases of hepatitis E. J Hepatol 2004;40:869-870.

12. Tesse $S$, Lioure B, Fornecker $L$, Wendling MJ, Stoll-Keller F, BigailIon $C$, et al. Circulation of genotype 4 hepatitis $E$ virus in europe: First autochthonous hepatitis $E$ infection in france. J Clin Virol 2012;54:197-200

13. Brost S, Wenzel JJ, Ganten TM, Filser M, Flechtenmacher C, Boehm $S$, et al. Sporadic cases of acute autochthonous hepatitis $E$ virus infection in southwest germany. J Clin Virol 2010;47:89-92.

14. Kruttgen $A$, Scheithauer $S$, Hausler M, Kleines M. First report of an autochthonous hepatitis $E$ virus genotype 3 infection in a 5 month old female child in germany. J Clin Virol 2011;50:175-176.

15. Ishida S, Yoshizumi S, Miyoshi M, Okui T, Ishida A, Abe S, et al. A cluster of hepatitis E virus infection in hokkaido, japan. Jpn J Infect Dis 2006;59:135-136.
16. Yazaki Y, Mizuo H, Takahashi M, Nishizawa T, Sasaki N, Gotanda $Y$, et al. Sporadic acute or fulminant hepatitis $E$ in Hokkaido, Japan, may be food-borne, as suggested by the presence of hepatitis $E$ virus in pig liver as food. J Gen Virol 2003;84:2351-2357.

17. Jeong SH. Current status of hepatitis e virus infection in Korea. Gut Liver 2011;5:427-431.

18. Lim JW, Park CS, Ahn JM, Yu MH, Kim TS, Lim YS, et al. Nine cases of sporadic acute hepatitis $\mathrm{E}$ in Korea. Korean J Hepatol 2006;12:230-236.

19. Kim DH, Park H, Moon SW, Jeong JH, Yang HS, Kim do H, et al. Three sporadic cases of acute hepatitis E. Korean J Gastroenterol 2007:50:121-125.

20. Kim SE, Kim MY, Kim DG, Song YJ, Jeong HJ, Lee SW, et al. Determination of fecal shedding rates and genotypes of swine hepatitis $E$ virus (HEV) in Korea. J Vet Med Sci 2008;70:1367-1371.

21. Jang JH, Jung YM, Kim JS, Lee SH, Kim JW, Hwang SG, et al. Coexistence of IgM antihepatitis $A$ virus and IgM antihepatitis $E$ virus in acute viral hepatitis: a prospective, multicentre study in Korea. J Viral Hepat 2011;18:e408-e414.

22. Kim YM, Jeong SH, Kim JY, Song JC, Lee JH, Kim JW, et al. The first case of genotype 4 hepatitis $\mathrm{E}$ related to wild boar in South Korea. J Clin Virol 2011;50:253-256. 